\title{
Wide-field optical coherence tomography in ABCA4- associated inherited retinal dystrophies
}

\author{
Mohammad Saleh ${ }^{1}$, Heidi Stöhr ${ }^{2}$, Christina Kiel ${ }^{2}$, Simone Kellner ${ }^{1,3}$, Silke Weinitz ${ }^{1,3}$, Ghazaleh Farmand ${ }^{1}$, \\ Bernhard H. F. Weber ${ }^{2,4}$, Albrecht Lommatzsch ${ }^{5,6}$, Ulrich Kellner ${ }^{1,3}$ \\ ${ }^{1}$ Rare Retinal Disease Center, AugenZentrum Siegburg, MVZ Augenärztliches Diagnostik- und Therapiezentrum Siegburg GmbH, \\ Siegburg 53721, Germany. \\ ${ }^{2}$ Institute of Human Genetics, University of Regensburg, Regensburg 93053, Germany. \\ ${ }^{3}$ RetinaScience, Bonn 53192, Germany. \\ ${ }^{4}$ Institute of Clinical Human Genetics, University Hospital Regensburg, Regensburg 93053, Germany. \\ ${ }^{5}$ Eye Care Center at St. Franziskus Hospital Münster, Münster 48145, Germany. \\ ${ }^{6}$ Achim-Wessing-Institute for Ophthalmologic Diagnostics, University Hospital Essen, Essen 45147, Germany.
}

Correspondence to: Mohammad Saleh, Rare Retinal Disease Center, AugenZentrum Siegburg, MVZ Augenärztliches
Diagnostik- und Therapiezentrum Siegburg GmbH, Europaplatz 3, Siegburg 53721, Germany. E-mail: M.Saleh@osg.de

How to cite this article: Saleh M, Stöhr H, Kiel C, Kellner S, Weinitz S, Farmand G, Weber BHF, Lommatzsch A, Kellner U. Widefield optical coherence tomography in ABCA4-associated inherited retinal dystrophies. J Trans/ Genet Genom 2021;5:250-64. https://dx.doi.org/10.20517/jtgg.2021.23

Received: 25 Apr 2021 First Decision: 30 Jun 2021 Revised: 11 Jul 2021 Accepted: 20 Jul 2021 First online: 20 Jul 2021

Academic Editor: Sanjay Gupta Copy Editor: Yue-Yue Zhang Production Editor: Yue-Yue Zhang

\begin{abstract}
Aim: With a need to expand the monitoring options in therapeutic clinical trials, we evaluated the additional information provided by wide-field optical coherence tomography (W-OCT) compared to conventional macular volume scan OCT (M-OCT) in ABCA4 gene-associated inherited retinal dystrophies (ABCA4-IRD).
\end{abstract}

Methods: A consecutive series of 52 ABCA4-IRD patients (mean age at last examination: 35.9 years, range 8.868.7 years) was examined between 2015 and 2021. Ophthalmologic examination included clinical examination, MOCT [20 × 20 degree field $(6.2 \mathrm{~mm} \times 6.2 \mathrm{~mm})]$, W-OCT [55 $\times 25$ degree field $(16.1 \mathrm{~mm} \times 7.3 \mathrm{~mm})]$, multicolor reflectance photography, fundus (FAF), and near-infrared autofluorescence (NIA) in macular and wide-field mode. Molecular genetic testing to confirm the clinical phenotype was performed in all patients.

Results: In 37/52 (71.2\%) of patients W-OCT revealed alterations of the outer retinal layers beyond the area covered by M-OCT at their last examination. In 15 patients, lesions were located within the area covered by MOCT. Lesions beyond M-OCT consisted of subretinal material (31/37), as well as patches (18/37) or large

The Author(s) 2021. Open Access This article is licensed under a Creative Commons Attribution 4.0 International License (https://creativecommons.org/licenses/by/4.0/), which permits unrestricted use, sharing, adaptation, distribution and reproduction in any medium or format, for any purpose, even commercially, as long as you give appropriate credit to the original author(s) and the source, provide a link to the Creative Commons license, and indicate if changes were made. 
continuous areas (3/37) of photoreceptor and retinal pigment epithelial dystrophy. In one patient, W-OCT identified peripheral lesions that were not detectable in wide-field FAF and NIA. In 48/52 patients, two causative mutations in the $A B C A 4$ gene were identified, while the remaining four patients carried one pathogenic $A B C A 4$ variant.

Conclusion: W-OCT as well as wide-field FAF and NIA document lesions in the retinal mid- and far periphery in the majority of ABCA4-IRD patients and provide means for detailed analysis of progression and future treatment planning and monitoring.

Keywords: ABCA4, inherited retinal dystrophies, optical coherence tomography, fundus autofluorescence, nearinfrared autofluorescence, wide-field imaging

\section{INTRODUCTION}

$A B C A 4$-associated inherited retinal dystrophies (ABCA4-IRD) present predominantly as autosomal recessive macular dystrophy (Stargardt disease) or autosomal recessive cone-rod dystrophy, but they can also present as autosomal recessive retinitis pigmentosa, autosomal recessive cone dystrophy, and agerelated macular degeneration type $2^{[1]}$. Thus far, 1530 genetic variants have been described in the $A B C A 4$ gene and classified as variants of disparate severity on the clinical phenotype expression ${ }^{[2-4]}$. Although clinical manifestations of ABCA4-IRD can be variable, lesions are usually similar in both eyes of one patient. Generally, fleck-like lesions and atrophic alterations initially manifest at the posterior pole, and during progression areas outside of the macula present alterations visible on ophthalmoscopy.

Detailed retinal imaging, identifying more lesions than are clinically visible, has demonstrated characteristic alterations of ABCA4-IRD on fundus autofluorescence (FAF), near-infrared autofluorescence (NIA), and optical coherence tomography $(\mathrm{OCT})^{[5-8]}$. Typical findings are fleck-like lesions with increased or reduced FAF or NIA intensity, partially corresponding to subretinal material (SRM) on OCT as well as focal or widespread areas with markedly reduced FAF and NIA intensity corresponding to photoreceptor and retinal pigment epithelial (RPE) loss on OCT. Whereas wide-field imaging for FAF and NIA has been used for more than 16 years, wide-field OCT (W-OCT) extending peripherally of the macular area has only become available recently. Until now, the relevance of W-OCT imaging has predominantly been evaluated with respect to repeatability of measurements ${ }^{[9]}$; normal retinal structures, especially the nerve fiber layer and choroidal layers ${ }^{[10-17]}$; and glaucoma-associated pathologies ${ }^{[18-22]}$. Studies regarding retinal disorders focused on diabetic retinopathy ${ }^{[23-27]}$, central serous chorioretinopathy ${ }^{[28]}$, or alterations associated with myopia ${ }^{[29,30]}$, whereas retinal dystrophies have rarely been examined by $\mathrm{W}-\mathrm{OCT}^{[31-34]}$ and, if so, only in small patient series. When comparing these W-OCT studies, it has to be kept in mind that the terms "wide-field" and "ultra-wide-field" have been used for similar ranges of measured areas, and sometimes the measured area has not been reported and can only be surmised from the presented images.

In the present study, we evaluated the information provided by W-OCT [ $55 \times 25$ degree field $(16.1 \mathrm{~mm} \times$ $7.3 \mathrm{~mm})$ ] compared to conventional macular OCT [M-OCT; $20 \times 20$ degree field $(6.2 \mathrm{~mm} \times 6.2 \mathrm{~mm})$ ] in a large series of genetically confirmed ABCA4-IRD patients.

\section{METHODS}

Included in this study was a consecutive series of unrelated patients with ABCA4-IRD who underwent WOCT imaging during their initial or follow-up visit in a specialized IRD center between September 2015 and January 2021. ABCA4-IRD was defined as the presence of two likely pathogenic or pathogenic $A B C A 4$ gene mutations or a single likely pathogenic or pathogenic $A B C A 4$ gene mutation with clinical findings 
consistent with ABCA4-IRD [Table 1]. ABCA4 variants were classified based on the standards and guidelines recommended by the American College of Medical Genetics and Genomics and the Association for Molecular Pathology ${ }^{[35]}$. Molecular genetic testing was performed in 9 patients by ABCR genotyping microarray (ABCR400 chip) ${ }^{[36]}, 2$ patients by a custom designed resequencing array (RetChip) ${ }^{[4]}$, and 41 patients by Next Generation Sequencing using targeted gene panels including $A B C A 4$ and a variable number of other genes that have been associated with macular dystrophy ${ }^{[4]}$. Additional causal sequence changes in other genes than $A B C A 4$ have not been identified in this group of patients.

All patients underwent clinical ophthalmological examination as well as detailed retinal imaging following informed consent after detailed explanation about the background of the study. The study was performed in adherence to the tenets of the Declaration of Helsinki. All applicable institutional and governmental regulations concerning the ethical use of human volunteers were followed during this research.

\section{Retinal imaging}

Retinal imaging including multicolor spectral reflectance imaging, FAF, NIA, and OCT were performed as described previously ${ }^{[5]}$. All images were obtained after medical dilatation of the pupil (phenylephrine 2.5\% and tropicamide $1 \%$ achieving a minimal diameter of $5 \mathrm{~mm}$ ) by trained retinal imaging specialists. FAF and NIA were obtained with a confocal scanning laser ophthalmoscope (Heidelberg Retina Angiograph 2, Heidelberg Engineering, Heidelberg, Germany) using $30^{\circ}$ (M-FAF, M-NIA) and $55^{\circ}$ lenses (W-FAF, WNIA). Multicolor spectral reflectance images and OCT were obtained with a spectral domain OCT (Spectralis OCT, Heidelberg Engineering, Heidelberg, Germany). A standard volume scan macular OCT (M-OCT) was recorded using $49 \mathrm{~B}$-scans with a distance between B-scans of $129 \mu \mathrm{m}$ in a $20 \times 20$ degree field $(6.2 \mathrm{~mm} \times 6.2 \mathrm{~mm})$ using ART mode with 16 images averaged. A wide-field (W-OCT) was recorded using $31 \mathrm{~B}$-scans with a distance between B-scans of $245 \mu \mathrm{m}$ in a $55 \times 25$ degree field $(16.1 \mathrm{~mm} \times 7.3 \mathrm{~mm})$ using ART mode with 16 images averaged. All images were evaluated by two observers (Saleh M and Kellner U), and W-OCT images were compared to M-OCT as well as M-/W-FAF and M-/W-NIA findings. Lesions detected on retinal imaging were similar on both eyes in nearly all patients; therefore, the results are presented combined for both eyes. In two patients (\#38 and \#52), the results of the more severely affected eye were selected. In addition, unilateral focal choroidal excavation was identified in three patients (\#12, $\# 44$, and \#48).

\section{Statistical analysis}

Correlation of the ABCA4 genotype with lesions detected by W-OCT was determined by applying a Fisher's exact test for count data implemented in the statistical programming software $\mathrm{R}^{[37]}$. Differences in age distributions were evaluated by a two-sided $t$ test for independent samples by the $t$ test function implemented in R. Statistical significance was defined by a $P$-value below 0.05 .

\section{RESULTS}

Fifty-two unrelated ABCA4-IRD patients were included in this study (32 females, 20 males; Table 2). The age at first examination ranged 7-66 years, and it ranged 8-68 years at last examination. W-OCTs could be recorded in 50/52 patients using $31 \mathrm{~B}$-scans. Due to problems with fixation, in one patient the scan pattern was reduced to $11 \mathrm{~B}$-scans and in one patient only single B-scans were possible. Clinical findings as well as retinal imaging results identified similar characteristics in both eyes of all patients except when specifically mentioned.

\section{W-OCT vs. M-OCT}

Macular alterations on M-OCT and W-OCT presented as photoreceptor and RPE atrophy $(n=34)$, foveal or perifoveal subretinal material (SRM; $n=8$ ), a preserved foveal island with perifoveal atrophy $(n=4)$, a 
Table 1. ABCA4 gene sequence variants identified in 52 patients with IRD

\begin{tabular}{|c|c|c|c|c|c|}
\hline Patient_ID & Allel 1 (DNA) & Allel 1 (Protein) & Allel 2 (DNA) & Allel 2 (Protein) & Group \\
\hline 1 & c.2588G>C(;)5603A>T & p.[Gly863Ala,Gly863del](;)(Asn1868Ile) & c. $4469 \mathrm{G}>\mathrm{A}$ & p.(Cys1490Tyr) & 3 \\
\hline 2 & c. $1609 C>T$ & p.(Arg537Cys) & c. $2588 \mathrm{G}>\mathrm{C}(;) 5603 \mathrm{~A}>\mathrm{T}$ & p.[Gly863Ala,Gly863del](;)(Asn1868lle) & 3 \\
\hline 3 & c.768G > T & p.[(Val256=),(Leu257Valfs*17)] & c. $5882 \mathrm{G}>\mathrm{A}$ & p.(Gly1961Glu) & 2 \\
\hline 4 & c. $3113 C>T$ & p.(Ala1038Val) & c.5461-10T>C(;)5603A>T & p. $\left(\right.$ Thr1821Valfs*13)/p. (Thr1821Aspfs $\left.{ }^{\star} 6\right)$ & 3 \\
\hline 5 & c. $5413 A>G$ & p.(Asn1805Asp) & c.4880_4903dup & p.(Leu1627_Ala1634dup) & 3 \\
\hline 6 & c. $1622 T>C(;) 3113 C>T$ & p.(Leu541Pro)(;)(Ala1038Val) & c. $5882 \mathrm{G}>\mathrm{A}$ & p.(Gly1961Glu) & 2 \\
\hline 7 & c. $1622 T>C(;) 3113 C>T$ & p.(Leu541Pro)(;)(Ala1038Val) & c. $5882 \mathrm{G}>\mathrm{A}$ & p.(Gly1961Glu) & 2 \\
\hline 8 & c. $288 \mathrm{C}>\mathrm{A}$ & p.(Asn96Lys) & c.5603A $>T$ & p.(Asn1868lle) & 2 \\
\hline 9 & c.5461-10T>C(;)5603A>T & p. $($ Thr1821Valfs*13)/p. (Thr1821Aspfs*6) & c. $5714+5 G>A$ & p.? & 3 \\
\hline 10 & c. $5882 \mathrm{G}>\mathrm{A}$ & p.(Gly1961Glu) & c. $(6005+1$ _6006-1)_(6822+1_?)del & p.? & 2 \\
\hline 11 & c. $2041 C>T$ & p. $\left(\operatorname{Arg} 681^{\star}\right)$ & c. $5882 \mathrm{G}>\mathrm{A}$ & p.(Gly1961Glu) & 2 \\
\hline 12 & c. $286 \mathrm{~A}>\mathrm{G}$ & p.(Asn96Asp) & c.5461-10T>C(;)5603A >T & p. $\left(\right.$ Thr1821Valfs $\left.{ }^{\star} 13\right) / p .\left(T h r 1821\right.$ Aspfs $\left.^{\star} 6\right)$ & 3 \\
\hline 13 & c. $67-1 \mathrm{G}>\mathrm{C}$ & p.? & c. $67-1 \mathrm{G}>\mathrm{C}$ & p.? & 3 \\
\hline 14 & c. $4773+3 A>G$ & p.? & c.5461-10T>C(;)5603A >T & p. $\left(\right.$ Thr1821Valfs*13)/p. (Thr1821Aspfs $\left.{ }^{\star} 6\right)$ & 3 \\
\hline 15 & c. $2588 \mathrm{G}>\mathrm{C}(;) 5603 \mathrm{~A}>\mathrm{T}$ & p.[Gly863Ala,Gly863del](;)(Asn1868lle) & c. $2894 A>G$ & p.(Asn965Ser) & 3 \\
\hline 16 & c. $5196+1 \mathrm{G}>\mathrm{A}$ & p.? & c. $5882 \mathrm{G}>\mathrm{A}$ & p.(Gly1961Glu) & 2 \\
\hline 17 & c. $2588 \mathrm{G}>\mathrm{C}$ & p.(Gly863Ala, G863del) & c. $3259 \mathrm{G}>\mathrm{A}$ & p.(Glu1087Asp) & 1 \\
\hline 18 & c.5461-10T>C & p. $($ Thr1821Valfs*13)/p. (Thr1821Aspfs*6) & c. $5882 \mathrm{G}>\mathrm{A}$ & p.(Gly1961Glu) & 2 \\
\hline 19 & c. $2588 \mathrm{G}>\mathrm{C}(;) 5603 \mathrm{~A}>\mathrm{T}$ & p.[Gly863Ala,Gly863del](;)(Asn1868Ile) & c. $2893 \mathrm{~A}>\mathrm{G}$ & p.(Asn965Asp) & 3 \\
\hline 20 & $c .3323 G>T$ & p.(Arg1108Leu) & c. $5882 \mathrm{G}>\mathrm{A}$ & p.(Gly1961Glu) & 2 \\
\hline 21 & c. $2609 C>T$ & p.(Pro870Leu) & c. $5908 \mathrm{C}>\mathrm{T}$ & p.(Leu1970Phe) & 1 \\
\hline 22 & c. $2291 \mathrm{G}>\mathrm{A}$ & p.(Cys764Tyr) & - & - & 1 \\
\hline 23 & c. $5510 C>T ; 5527 C>T$ & p.(Pro1837Leu);(Arg1843Trp) & c. $3113 C>T$ & p.(Ala1038Val) & 3 \\
\hline 24 & c. $5882 \mathrm{G}>\mathrm{A}$ & p.(Gly1961Glu) & c.5917del & p. $($ Val1973*) & 2 \\
\hline 25 & c. $4195 \mathrm{G}>\mathrm{A}$ & p.(Glu1399Lys) & c. $4234 \mathrm{C}>\mathrm{T}$ & p. $\left(\mathrm{G} \ln 1412^{\star}\right)$ & 3 \\
\hline 26 & c. $1832 T>C$ & p.(Leu611Pro) & c. $4102 C>T$ & p.(Arg1368Cys) & 3 \\
\hline 27 & c. $3482 \mathrm{G}>\mathrm{A}$ & p.(Arg1161His) & c. $5461-10 T>C(;) 5603 \mathrm{~A}>\mathrm{T}$ & p. $\left(\right.$ Thr1821Valfs*13)/p. (Thr1821Aspfs $\left.{ }^{\star} 6\right)$ & 3 \\
\hline 28 & c.194G>A & p.(Gly65Glu) & c. $1622 T>C(;) 3113 C>T$ & p.(Leu541Pro)(;)(Ala1038Val) & 3 \\
\hline 29 & c. $2588 \mathrm{G}>\mathrm{C}(;) 5603 \mathrm{~A}>\mathrm{T}$ & p.[Gly863Ala,Gly863del](;)(Asn1868lle) & c. $2588 \mathrm{G}>\mathrm{C}$ & p.(Gly863Ala, Gly863del) & 1 \\
\hline 30 & c.1622T>C(;)3113C>T & p.(Leu541Pro)(;)(Ala1038Val) & c. $5603 \mathrm{~A}>\mathrm{T}$ & p.(Asn1868lle) & 2 \\
\hline 31 & c. $1495 \mathrm{~T}>\mathrm{C}$ & p.(Trp499Arg) & c. $1903 C>T$ & p. $\left(G \ln 635^{\star}\right)$ & 3 \\
\hline 32 & c. $6229 \mathrm{C}>\mathrm{T}$ & p.(Arg2077Trp) & c. $5603 \mathrm{~A}>\mathrm{T}$ & p.(Asn1868lle) & 2 \\
\hline
\end{tabular}




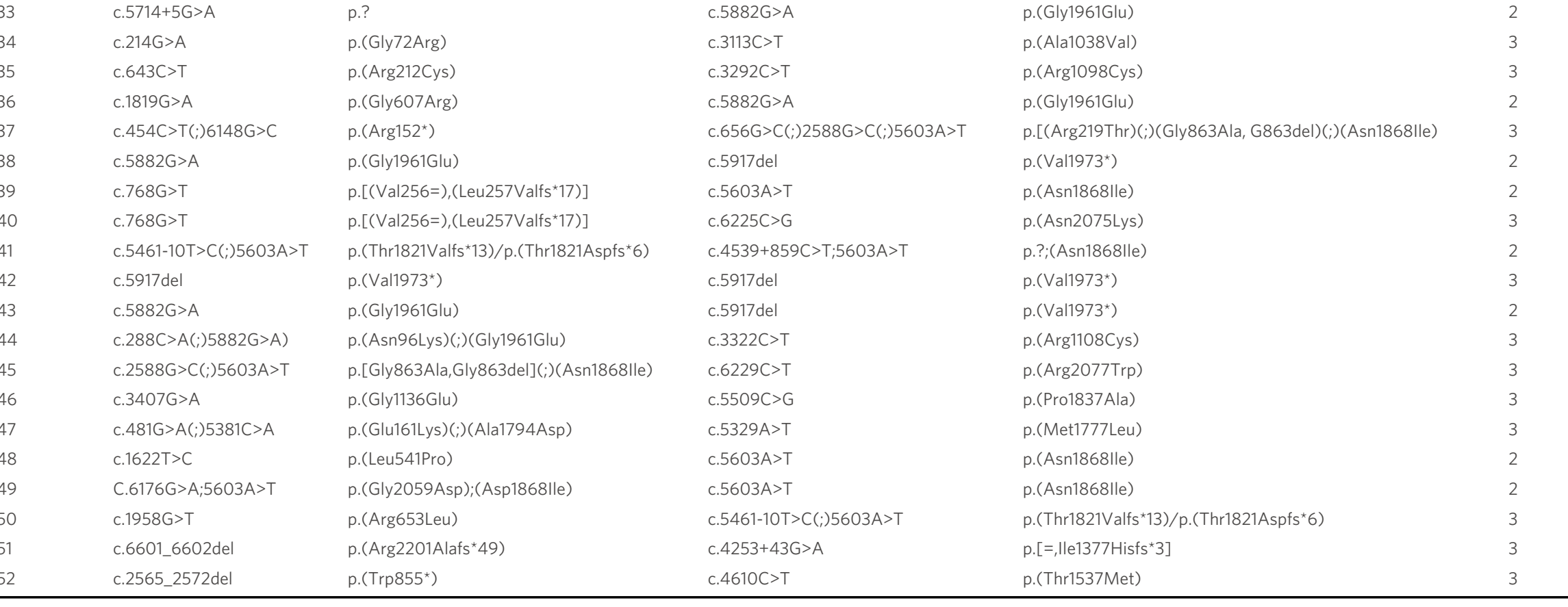

Reference sequence ABCA4: NM_000350.3. Patients assigned to Group 1 carry a single (likely) pathogenic mutation with or without an additional variant of unknown significance, patients in Group 2 carry a (likely) pathogenic in addition to a mild mutation, and patients assigned to Group 3 carry two (likely) pathogenic mutations.

combination of atrophy and SRM $(n=3)$, a combination of atrophy and unilateral foveal focal choroidal excavation $(n=2)$, and bilateral foveal cavitation $(n=$ 1) [Figures 1-7]. In one patient (\#52), a combination of atrophy and SRM was seen on the right eye, whereas the left eye showed SRM but no atrophic lesions. In addition, unilateral midperipheral focal choroidal excavation was observed in another patient [Figure 6].

In 15/52 patients (28.8\%), on both eyes no lesions beyond the area covered by M-OCT were observed either at the initial examination or at follow-up visits. In $37 / 52$ patients $(71.2 \%)$, retinal alterations extended beyond the area covered by M-OCT, which was unilateral only in one patient (\#38). The areas involved included temporal extension of macular involvement, lesions nasal of the disc, lesions beyond the vascular arcades, or lesions continuous towards the periphery. The severity of findings varied as SRM $(n=16)$, atrophic lesions and SRM $(n=15)$, focal atrophic lesions $(n=3)$, marked outer retinal disorganization $(n=2)$, and marked outer retinal disorganization in a scalloped pattern $(n=1)$. In addition, W-OCT revealed bilateral dome-shaped bulbus 


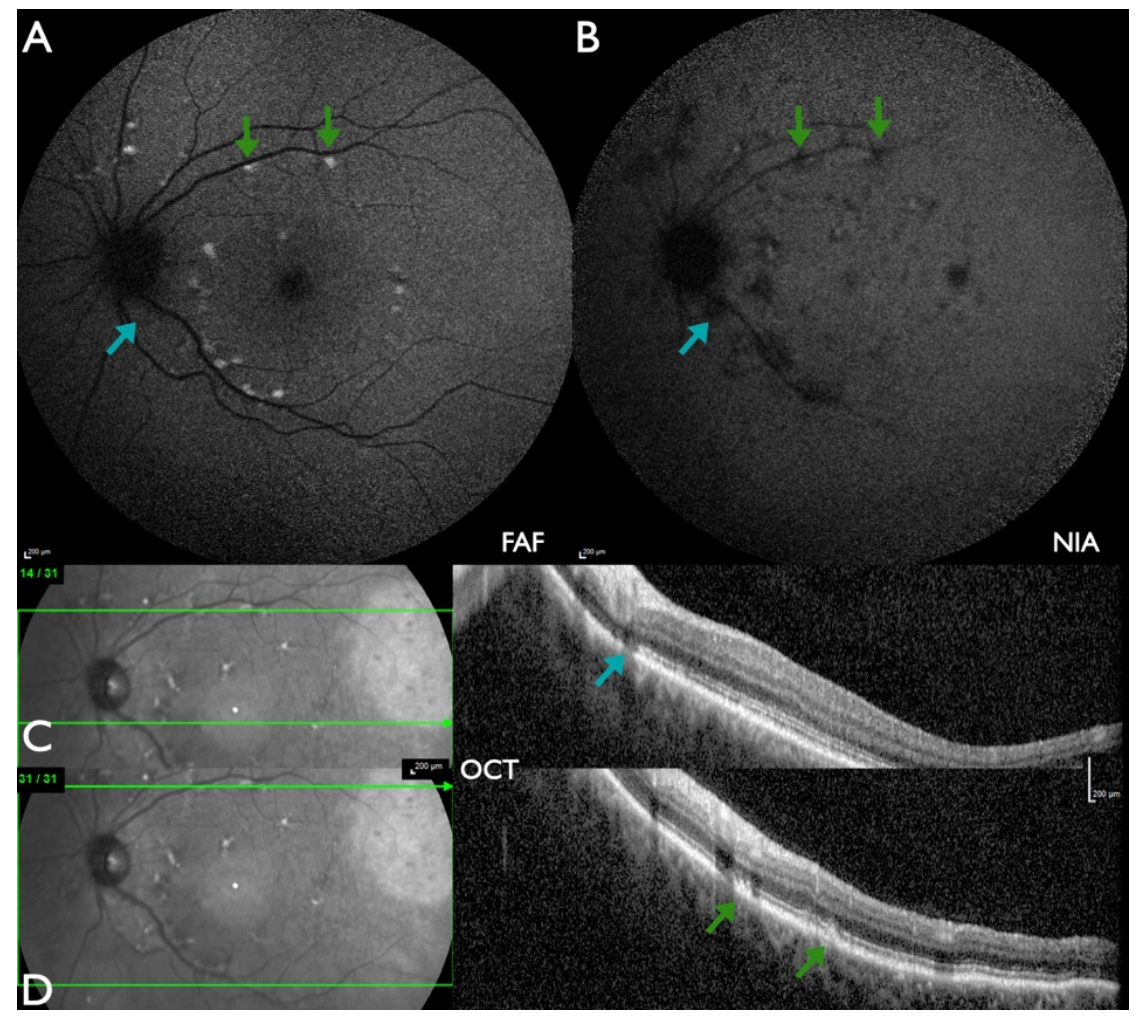

Figure 1. Patient \#33 (49.8 years) with mild ABCA4-IRD with limited alterations of the foveal area. (A) FAF: flecks with increased intensity at the border of the macula as well as superior to the optic disc. (B) NIA: mostly flecks with reduced intensity, including the fovea, and a few flecks with slightly increased intensity. (C) W-OCT: the horizontal green arrow on the fundus image indicates the location of the B-scan. The blue arrow indicates a fleck of outer segment loss, corresponding to a barely detectable loss of FAF intensity (A) and a marked loss of NIA intensity (B). (D) W-OCT: near the upper temporal vascular arcade flecks of subretinal material (SRM, green arrows) correspond to flecks of increased FAF intensity (A) and reduced NIA intensity (B).

configuration, marked posterior staphyloma, or optic disc drusen in one patient each.

\section{W-OCT vs. W-FAF}

In this series of 52 patients, W-FAF was obtained in all patients, whereas W-NIA and M-NIA could only be obtained in 49/52 patients. W-OCT did not identify lesions beyond the area covered by M-OCT that were not detected by W-FAF or W-NIA as well except for one patient (\#35) with SRM in areas of normal W-FAF and W-NIA. The retinal characteristics of the lesions identified on FAF or NIA, e.g., whether there was focal atrophy or SRM, could be documented and followed over time by W-OCT [Figures 1-6]. Especially midperipheral focal choroidal excavation could not be identified on either W-FAF or W-NIA [Figure 6].

M-FAF lesions consisted of flecks of both increased and reduced intensity (20/52), flecks of increased intensity (13/52), flecks of reduced intensity (4/52), large atrophic areas (3/52), atrophic areas and flecks of both increased and reduced intensity (2/52), atrophic areas and flecks of increased intensity (1/52), a parafoveal ring with increased intensity (4/52), and a ring and flecks of either increased (3/52) or reduced intensity (2/52). W-FAF was normal in 15 patients. Peripheral lesions consisted of flecks of increased intensity (19/52), flecks of both increased and reduced intensity (9/52), flecks of reduced intensity (3/52), atrophic areas and flecks of both increased and reduced intensity (1/52), atrophic areas and flecks of increased intensity (3/52), and rings with increased intensity (2/52). FAF lesions with increased intensity corresponded in general to W-OCT lesions with SRM, whereas FAF lesions with reduced intensity 
Table 2. Retinal imaging findings at last examination

\begin{tabular}{|c|c|c|c|c|c|c|c|c|c|c|}
\hline \multirow[b]{2}{*}{ Patient_ID } & \multirow[b]{2}{*}{$\begin{array}{l}\text { Age last exam } \\
\text { (year) }\end{array}$} & \multirow[b]{2}{*}{$\begin{array}{l}\text { Follow-up } \\
\text { (year) }\end{array}$} & \multicolumn{2}{|r|}{ OCT } & \multicolumn{3}{|c|}{ FAF } & \multicolumn{3}{|c|}{ NIA } \\
\hline & & & M_OCT & W_OCT & M_FAF & W_FAF & PS & M_NIA & W_NIA & PS \\
\hline 1 & 29.5 & 0 & A & A, SRM & FRI & FRI & PS & $\mathrm{FR}$ & FR & PS \\
\hline 2 & 33.1 & 0 & A & SRM & $\mathrm{FI}$ & $\mathrm{FI}$ & PS & FRI & $\mathrm{FR}$ & PS \\
\hline 3 & 50.4 & 3 & A & SRM & FRI & $\mathrm{Fl}$ & PS & $\mathrm{FR}$ & FR & PS \\
\hline 4 & 27.5 & 4 & A & SRM & $\mathrm{RI}, \mathrm{Fl}$ & $\mathrm{Fl}$ & PS & $\mathrm{RI}, \mathrm{FR}$ & FR & PS \\
\hline 5 & 46.0 & 0 & A & A, post staphyloma & A & $\mathrm{A}, \mathrm{FI}$ & PS & A & $\mathrm{R}$ & PS \\
\hline 6 & 35.5 & 0 & A & SRM & $\mathrm{Fl}$ & $\mathrm{FI}$ & PS & A & FRI & PS \\
\hline 7 & 28.3 & 0 & A & Normal & FRI & Normal & NPI & FRI & Normal & NPI \\
\hline 8 & 33.0 & 0 & $A$ & Normal & $\mathrm{FI}$ & Normal & NPI & $\mathrm{RI}$ & Normal & NPI \\
\hline 9 & 43.6 & 3 & A & A, SRM & $\mathrm{A}, \mathrm{FI}$ & $\mathrm{A}, \mathrm{FI}$ & PS & A & $\mathrm{R}$ & PS \\
\hline 10 & 41.5 & 0 & A & $\begin{array}{l}\text { Normal, dome- } \\
\text { shaped }\end{array}$ & $\mathrm{Fl}$ & Normal & NPI & $\mathrm{R}$ & $\mathrm{R}$ & PS \\
\hline 11 & 34.0 & 0 & A & Normal & $\mathrm{Fl}$ & Normal & NPI & $\mathrm{FRI}$ & $\mathrm{R}$ & PS \\
\hline 12 & 26.4 & 4 & A & $\mathrm{A}, \mathrm{SRM}, \mathrm{FE}^{\star}$ & FR & FRI & NoPS & $\mathrm{R}$ & FR & NoPS \\
\hline 13 & 19.3 & 0 & A & A, SRM & $\mathrm{FR}$ & $\mathrm{FR}$ & NoPS & $\mathrm{R}$ & FR & NoPS \\
\hline 14 & 40.7 & 0 & A & A, SRM & FRI & FRI & PS & $\mathrm{R}$ & FR & PS \\
\hline 15 & 54.0 & 2 & A, PRI & A, SRM & $A, F R I$ & FRI & PS & $A, F R$ & FR & PS \\
\hline 16 & 26.5 & 3 & $\mathrm{FC}$ & Normal & $\mathrm{RI}$ & Normal & NPI & $\mathrm{RI}$ & $\mathrm{R}$ & PS \\
\hline 17 & 68.7 & 2 & SRM & SRM & FRI & $\mathrm{FI}$ & NoPS & $\mathrm{FRI}$ & $\mathrm{R}$ & ND \\
\hline 18 & 48.9 & 0 & A & A, SRM & FRI & $\mathrm{FI}$ & NoPS & $\mathrm{FRI}$ & FRI & NoPS \\
\hline 19 & 20.5 & 2 & A & SRM & FRI & $\mathrm{FI}$ & PS & $\mathrm{R}$ & $\mathrm{FR}$ & PS \\
\hline 20 & 33.3 & 0 & A & Normal & $\mathrm{FI}$ & Normal & NPI & FRI & Normal & NPI \\
\hline 21 & 28.5 & 0 & SRM & SRM & $\mathrm{FI}$ & $\mathrm{FI}$ & PS & FRI & $\mathrm{FR}$ & PS \\
\hline 22 & 46.4 & 3 & SRM & Normal & $\mathrm{FI}$ & Normal & NPI & $\mathrm{FI}$ & $\mathrm{R}$ & PS \\
\hline 23 & 14.6 & 2 & A & A, SRM & $\mathrm{RR}, \mathrm{FR}$ & $\mathrm{FRI}$ & PS & $\mathrm{R}$ & $\mathrm{FR}$ & PS \\
\hline 24 & 29.7 & 0 & $A$ & Normal & $\mathrm{RI}, \mathrm{FI}$ & Normal & $\mathrm{NPI}$ & ND & ND & ND \\
\hline 25 & 63.8 & 1 & A, PRI & SRM & FRI & $\mathrm{FI}$ & PS & FRI & $\mathrm{FR}$ & PS \\
\hline 26 & 50.5 & 0 & SRM & A, SRM & FRI & $\mathrm{FI}$ & PS & FRI & $\mathrm{FR}$ & PS \\
\hline 27 & 18.8 & 4 & A & SRM & $\mathrm{Fl}$ & $\mathrm{FI}$ & PS & $\mathrm{FR}$ & Normal & PS \\
\hline 28 & 29.9 & 0 & A & WA & FR & $\mathrm{FR}$ & PS & ND & ND & ND \\
\hline 29 & 9.5 & 0 & SRM & Normal & $\mathrm{FI}$ & Normal & $\mathrm{NPI}$ & $\mathrm{R}$ & Normal & NPI \\
\hline 30 & 26.4 & 0 & A & Normal & $\mathrm{Fl}$ & Normal & NPI & FR & Normal & NPI \\
\hline 31 & 43.8 & 0 & A & Scalloped WA & A & $\mathrm{A}, \mathrm{FI}$ & NoPS & A & MR & ND \\
\hline 32 & 37.6 & 0 & A, SRM & Normal & $\begin{array}{l}\text { FRI, Disc } \\
\text { Drusen }\end{array}$ & Normal & NPI & A & Normal & NPI \\
\hline 33 & 49.8 & 0 & SRM & SRM & $\mathrm{FI}$ & $\mathrm{FI}$ & PS & FRI & $\mathrm{FRI}$ & NoPS \\
\hline 34 & 28.8 & 0 & A & A, SRM & FRI & FRI & PS & ND & ND & ND \\
\hline 35 & 44.0 & 0 & A, PRI & SRM & FRI & Normal & NPI & A & Normal & NPI \\
\hline 36 & 23.9 & 2 & A & Normal & $\mathrm{RR}, \mathrm{FR}$ & Normal & $\mathrm{NPI}$ & $\mathrm{RI}, \mathrm{FR}$ & Normal & NPI \\
\hline 37 & 46.3 & 0 & A & A, SRM & FRI & FRI & PS & FRI & $\mathrm{R}$ & PS \\
\hline 38 & 42.2 & 0 & A & $\mathrm{SRM}^{\star}$ & FRI & $\mathrm{FI}$ & PS & FRI & FR & PS \\
\hline 39 & 50.4 & 0 & A & SRM & FRI & $\mathrm{Fl}$ & PS & FRI & FR & PS \\
\hline 40 & 19.8 & 0 & A & SRM & FRI & $\mathrm{Fl}$ & PS & $\mathrm{FR}$ & FR & PS \\
\hline 41 & 65.5 & 1 & A & A, SRM & FRI & $\mathrm{Fl}$ & PS & FR & FR & NoPS \\
\hline 42 & 11.2 & 0 & A & A & $A$ & RI & PS & $\mathrm{R}$ & $\mathrm{R}$ & PS \\
\hline 43 & 27.9 & 0 & A & Normal & $\mathrm{RI}$ & Normal & NPI & $\mathrm{RI}$ & $\mathrm{R}$ & PS \\
\hline 44 & 38.7 & 0 & $\mathrm{~A}, \mathrm{FE}^{\star}$ & A, SRM & $\mathrm{RI}, \mathrm{FI}$ & $\mathrm{FRI}$ & PS & $\mathrm{R}$ & $\mathrm{R}$ & PS \\
\hline 45 & 33.2 & 0 & A, PRI & A, SRM & FRI & $\mathrm{Fl}$ & PS & FRI & FRI & PS \\
\hline 46 & 8.8 & 1 & A & WA & $\mathrm{FR}$ & FR & PS & $\mathrm{R}$ & $\mathrm{R}$ & PS \\
\hline
\end{tabular}




\begin{tabular}{|c|c|c|c|c|c|c|c|c|c|c|}
\hline 47 & 35.2 & 1 & A & A & RI & RI & NoPS & A & $\mathrm{R}$ & NoPS \\
\hline 48 & 33.7 & 0 & $\mathrm{~A}, \mathrm{FE}^{\star}$ & Normal & $\mathrm{RI}$ & Normal & NPI & $F R$ & Normal & NPI \\
\hline 49 & 38.1 & 0 & SRM & SRM & A, FRI & $\mathrm{A}, \mathrm{FRI}$ & NoPS & A, FRI & $\mathrm{FR}$ & NoPS \\
\hline 50 & 10.7 & 0 & A, SRM & SRM & FRI & FRI & NoPS & FR & FR & NoPS \\
\hline 51 & 60.8 & 0 & A, SRM & SRM & FRI & $\mathrm{FI}$ & PS & FRI & FRI & NoPS \\
\hline 52 & 55.4 & 0 & SRM & $A^{\star}, S R M$ & $\mathrm{FI}$ & $\mathrm{FI}$ & PS & FRI & $\mathrm{FR}$ & PS \\
\hline
\end{tabular}

Optical coherence tomography (OCT) - A: areas of outer layer atrophy; FC: foveal cavitation; FE: focal choroidal excavation; PRI: preserved foveal island; SRM: subretinal material; WA: widespread areas of outer layer atrophy. Fundus autofluorescence (FAF)/near-infrared autofluorescence (NIA) - A: areas of absent FAF/NIA intensity; Fl: flecks with increased intensity; FR: flecks with reduced intensity; FRI: flecks with increased or reduced intensity; MR: markedly reduced intensity; ND: not done; NPI: no peripapillary involvement; NoPS: absence of peripapillary sparing; PS: peripapillary sparing; R: generally reduced intensity; RI: ring with increased intensity; RR: ring with reduced intensity; *indicates unilateral findings.

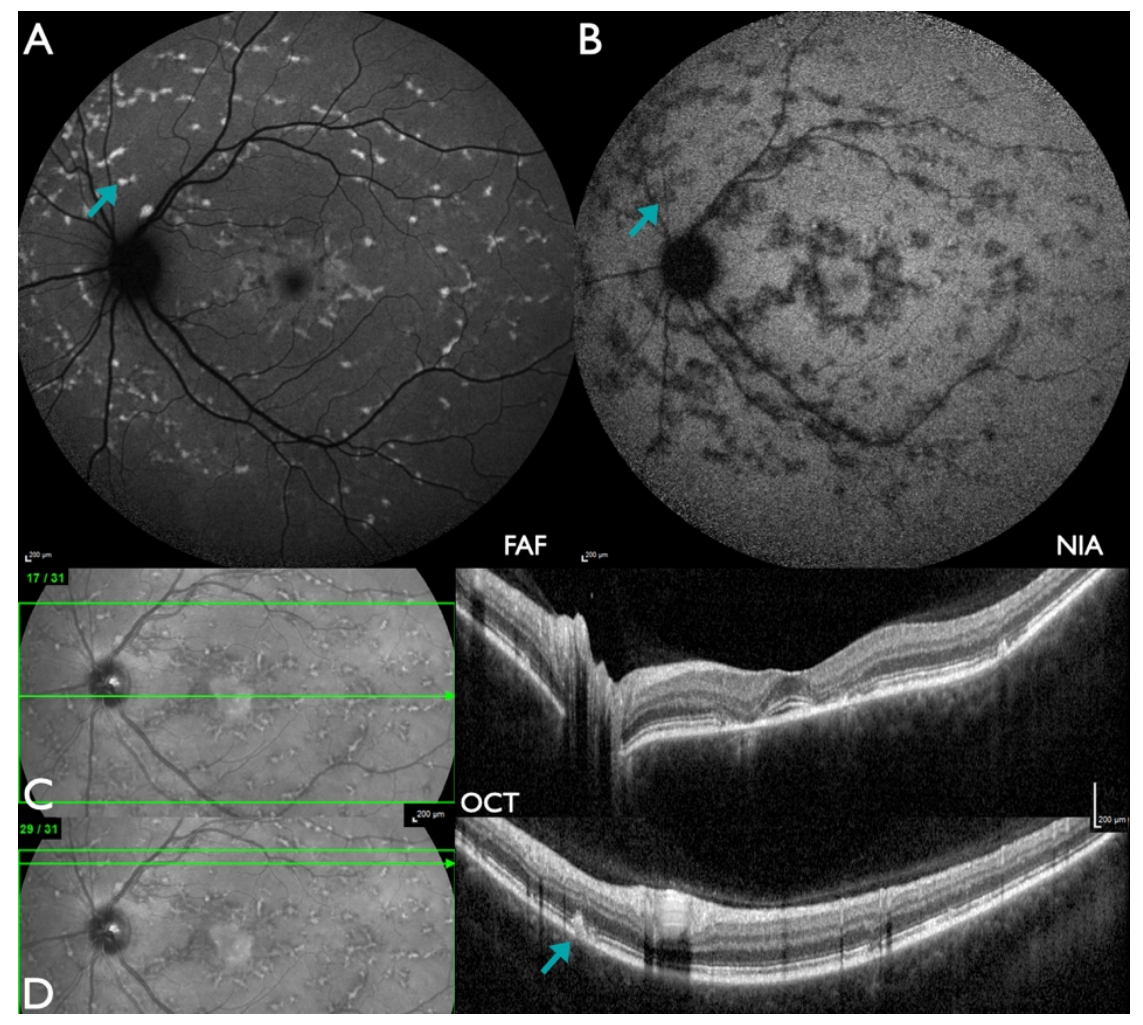

Figure 2. Patient \#45 (33.2 years) with moderate ABCA4-IRD with perifoveal atrophy. (A) FAF: multiple flecks with increased intensity in the macula as well as beyond the vascular arcades with peripapillary sparing, in addition to a parafoveal area of slightly increased intensity. (B) NIA: multiple flecks with reduced intensity, including the fovea and a parafoveal ring with peripapillary sparing, as well as a few flecks with slightly increased intensity. (C) W-OCT: paracentral loss of outer retinal layers corresponds to slightly increased FAF intensity (A) and a marked loss of NIA intensity (B). (D) W-OCT: near the upper temporal vascular arcade, flecks of subretinal material (SRM, blue arrow) correspond to flecks of increased FAF intensity (A) and reduced NIA intensity (B).

corresponded to W-OCT lesions with either intact or atrophic outer retinal layers. Preservation of the peripapillary region (peripapillary sparing) could not be defined in patients with lesions confined to the macular region (15/52) and was noted in the majority of patients with peripheral lesions (29/37). However, 8/37 patients did not show peripapillary sparing with lesions in contact to the optic disc.

\section{W-OCT vs. W-NIA}

NIA identified more extensive lesions compared to FAF [Figures 1-6]. M-NIA lesions consisted of flecks of both increased and reduced intensity (16/49), generally reduced intensity (10/49), flecks of reduced intensity 


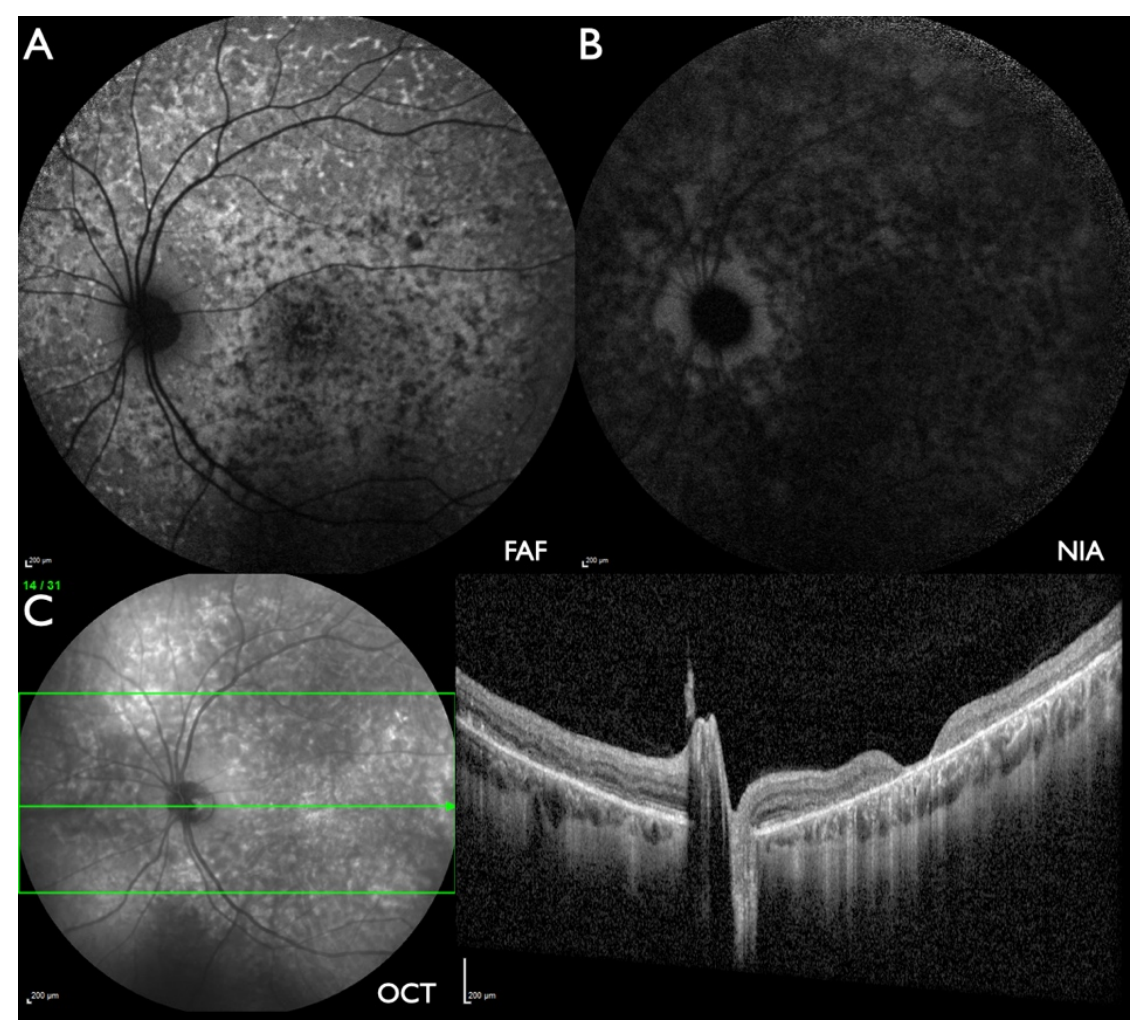

Figure 3. Patient \#1 (29.5 years) with marked ABCA4-IRD with macular atrophy. (A) FAF: multiple flecks with mostly increased intensity in the macula as well as beyond the vascular arcades with peripapillary sparing, in addition to central flecks of reduced intensity. (B) NIA: multiple flecks with markedly reduced intensity with peripapillary sparing and no flecks with increased intensity. (C) W-OCT: central loss of outer retinal layers as well as outer retinal irregularities nasal to the optic disc corresponding to FAF lesions with increased or reduced intensity (A) as well as NIA lesions with markedly reduced intensity.

(8/49), large atrophic areas (7/49), a parafoveal ring with increased intensity (3/49), a parafoveal ring with increased intensity and flecks of reduced intensity (2/49), flecks of increased intensity (1/49), atrophic areas and flecks of both increased and reduced intensity (1/49), or atrophic areas and flecks of reduced intensity (1/49). W-NIA was normal in 10/49 patients. Lesions beyond the vascular arcades consisted of flecks of reduced intensity (20/49), generally reduced intensity (14/49), and flecks of both increased and reduced intensity (5/49). NIA lesions with reduced intensity corresponded to either W-OCT lesions with SRM or atrophic outer retinal layers, indicating that different information is obtained by NIA compared to FAF. Therefore, a combination of FAF, NIA, and OCT provides the most detailed information on retinal lesions. Whereas the majority of patients showed peripapillary sparing on NIA as well (29/47), three patients with peripapillary sparing on FAF showed lesions adjacent to the optic disc on NIA [Figure 1].

\section{W-OCT follow up}

One or more W-OCT follow-up examinations were performed in 16/52 patients (30.8\%) about 1-4 years after the initial examination. The majority $(14 / 16)$ developed peripheral progression with involvement of more peripheral areas [Figure 7]. One patient with only macular lesions showed a slight increase of lesions size over a period of three years. The patient with bilateral foveal cavitation presented no alterations of the lesion after a period of three years.

\section{W-OCT and ABCA4 variants}

Out of the 52 patients, 48 carried either $\geq 2$ (likely) pathogenic $A B C A 4$ variants or the frequent 


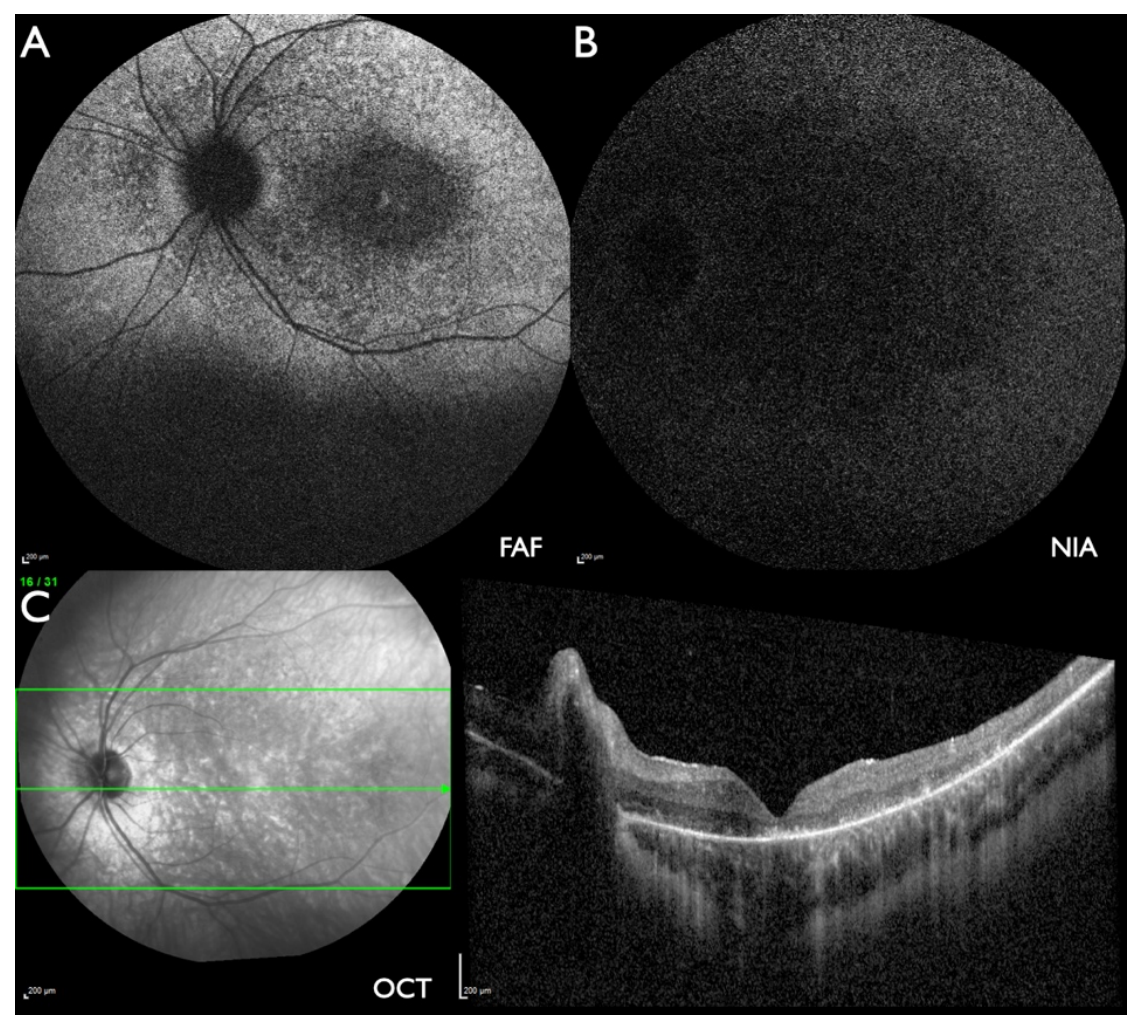

Figure 4. Patient \#46 (8.8 years) with severe ABCA4-IRD with macular and widespread peripheral atrophy. (A) FAF: centrally reduced intensity in an oval area as well as fleck-like variable intensity with only partial peripapillary sparing. (B) NIA: severely reduced intensity at the posterior pole and slightly less distinct beyond the vascular arcades. (C) W-OCT: severe irregularities of the outer retinal layers with few flecks of subretinal material.

hypomorphic c.5603A $>\mathrm{T}$ allele in combination with a (likely) pathogenic $A B C A 4$ variant. In 4 patients, a single heterozygous (likely) pathogenic $A B C A 4$ sequence change was identified (partially solved) (Group 1, Table 3). Peripheral lesions detected by W-OCT were less frequently observed in the 20 patients carrying the frequent mild alleles c.5603A $>\mathrm{T}$ or c.5882G $>\mathrm{A}$ in combination with a (likely) pathogenic $A B C A 4$ variant (13 without vs. 7 with W-OCT lesions, Group 2, Table 3). This difference was statistically significant (Fisher's exact test, $P$-value $\left.=4.02 \times 10^{-7}\right)$. In contrast, all 28 patients carrying $\geq 2$ (likely) pathogenic $A B C A 4$ variants (Group 3, Table 3) displayed W-OCT lesions. In Group 3, the mean age of patients was $34.10 \pm$ 15.47 years. In Group 2, the mean age of patients without W-OCT lesions was significantly lower $(t$ test, $P$ value $=0.0035)$ than the mean age of patients with W-OCT lesions ( $32.15 \pm 5.76$ years $v s .48 .37 \pm 9.79$ years), indicating that patients carrying mild $A B C A 4$ alleles may develop peripheral abnormalities later in life.

\section{DISCUSSION}

Although there is agreement that areas covered by retinal imaging should be extended to the retinal periphery, a succinct definition of the term "wide-field" or "ultra-wide-field" does not exist. In the present study, W-OCT was used in comparison to the frequently used macular volume scan (M-OCT). The widefield scan used in this study extended horizontally to 55 degrees $(16.1 \mathrm{~mm})$ and vertically to 25 degrees $(7.3$ $\mathrm{mm}$ ) as provided by the Heidelberg Engineering Spectralis design. Other manufacturers provide sweptsource OCTs with a $12 \mathrm{~mm} \times 9 \mathrm{~mm}$ field ${ }^{[20,30]}$. Future developments for OCTs intend to optimize resolution as well as extend the field of view ${ }^{[3,393]}$. 
Table 3. Correlation of ABCA4 genotype with lesions detected only by W-OCT

\begin{tabular}{llll}
\hline Group & Allel $\mathbf{1} /$ Allel $\mathbf{2}$ & No. of patients without lesions (mean age \pm SD) & No. of patients with lesions (mean age \pm SD) \\
\hline 1 & Pathogenic/+ & $2(27.95 \pm 26.09$ year $)$ & $2(48.6 \pm 28.43$ year $)$ \\
2 & Pathogenic/mild & $13(32.15 \pm 5.76$ year $)$ & $7(48.37 \pm 9.79$ year $)$ \\
3 & Pathogenic/pathogenic & - & $28(34.10 \pm 15.47$ year $)$ \\
\hline
\end{tabular}

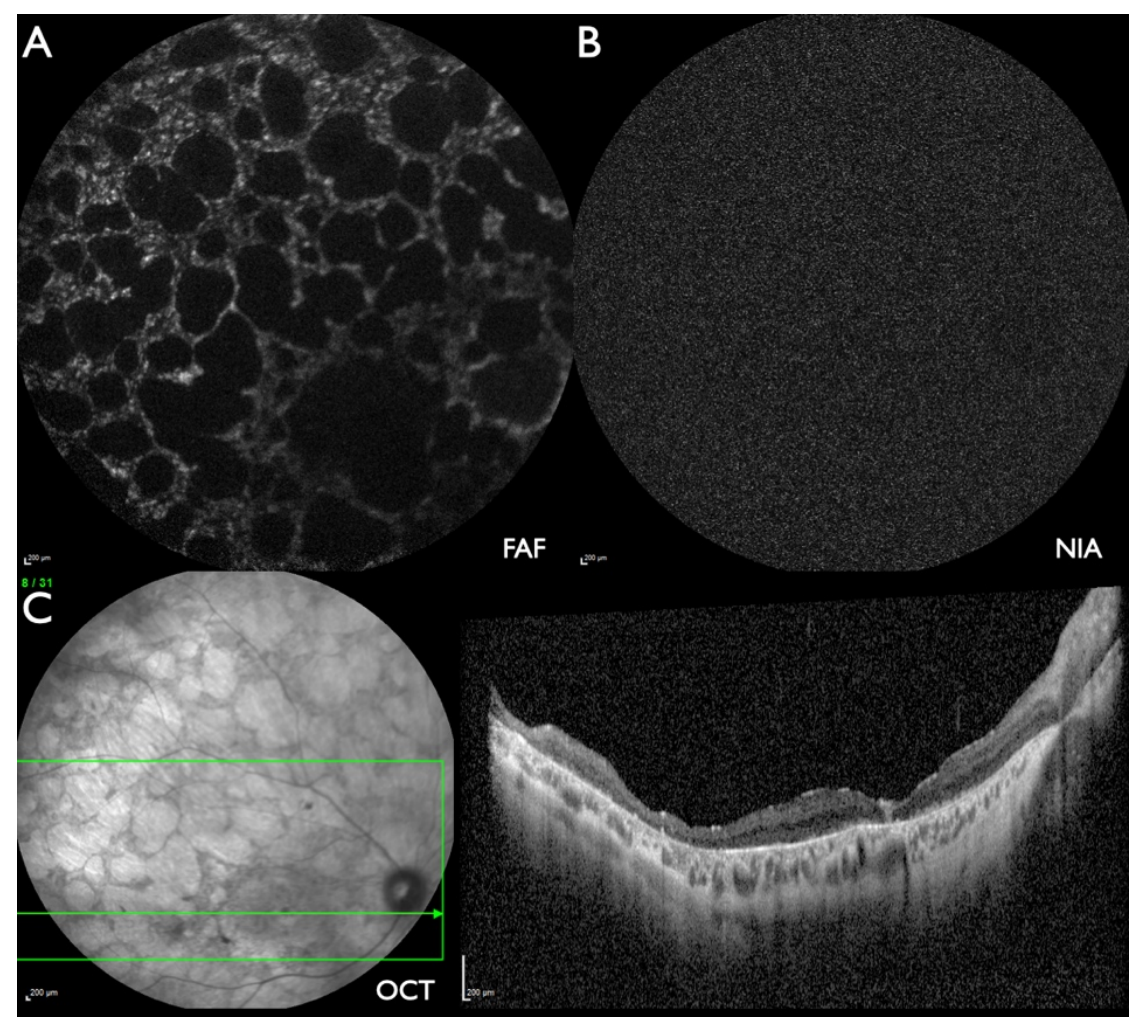

Figure 5. Patient \#31 (43.8 years) with severely progressed ABCA4-IRD with widespread scalloped atrophy. (A) FAF: multiple areas of absent FAF intensity bordered by areas with fleck-like reduced or increased intensity without peripapillary sparing, in addition to a parafoveal area of slightly increased intensity. (B) NIA: no measurable intensity. (C) W-OCT: increased reflectance in all retinal layers in the fovea. Marked disintegration of retinal layers over the whole length of the scan.

Examining larger retinal areas requires longer examination times, and therefore sufficient fixation and increased independence of eye movement are important. With the present technique, in 50/52 patients, high-resolution W-OCTs could be obtained. This is important, as the majority of patients had reduced visual acuity and problems with fixation. The present study showed that W-OCT is a feasible method for the examination of ABCA4-IRD patients.

W-OCT identified retinal lesions outside the area covered by M-OCT in the majority of patients. Patients without W-OCT abnormalities carried either a single causative $A B C A 4$ mutation or a mild $A B C A 4$ variant in combination with a severe variant, which is consistent with previous observations that the presence of mild alleles results in a late-onset and/or milder phenotype ${ }^{[40]}$.

Although, except for one patient, the more peripheral W-OCT lesions were also identified by W-FAF and W-NIA, W-OCT added important information, not in respect to the location of the lesion but regarding the intraretinal alterations corresponding to W-FAF and W-NIA findings. Therefore, W-OCT provides an 

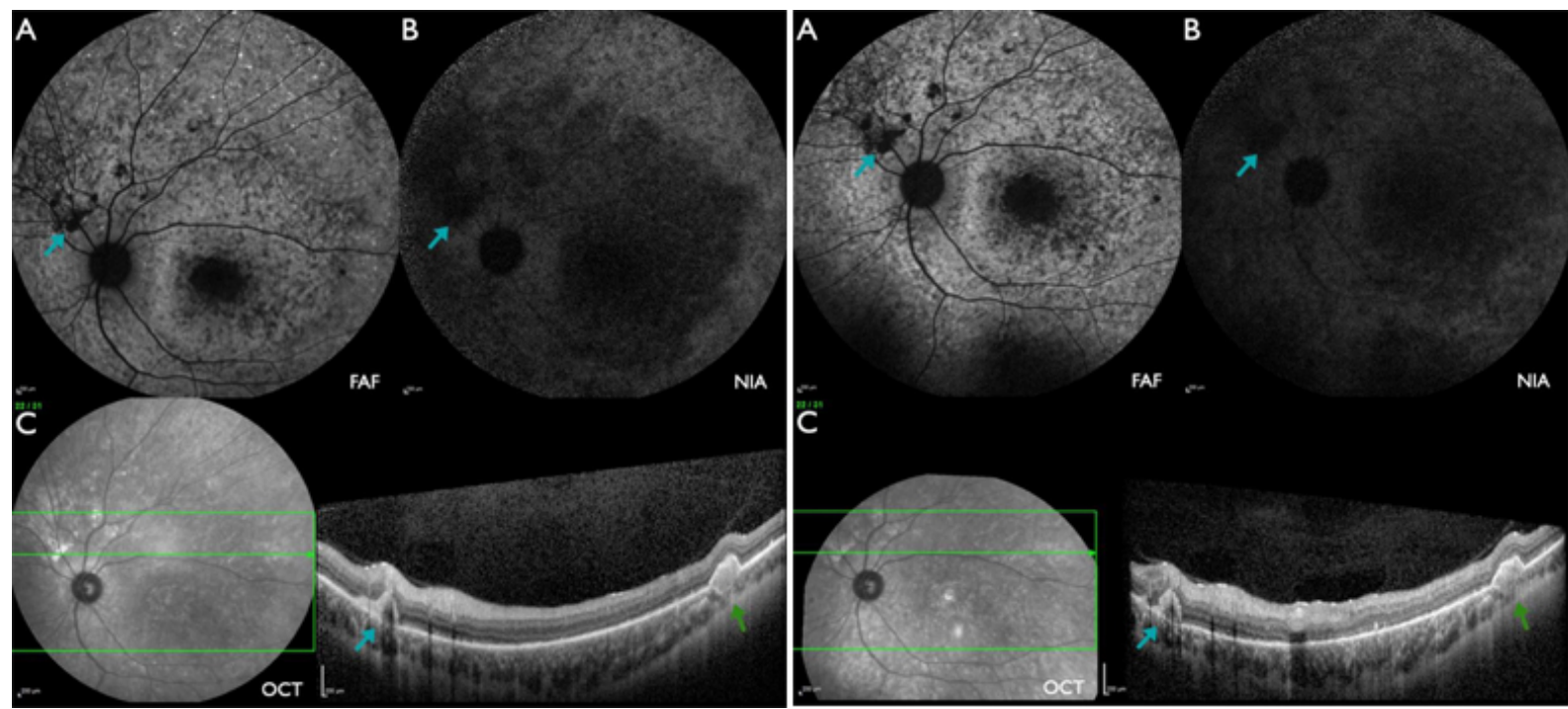

Figure 6. Patient \#12 [22.6 (left) and 26.4 years (right)] with severe ABCA4-IRD with macular and peripheral atrophy. (A) FAF: multiple flecks with increased or reduced intensity with peripapillary sparing. (B) NIA: centrally large areas and towards the periphery flecks with reduced intensity, peripapillary sparing. (C) W-OCT: subretinal material (blue arrow) corresponds to areas of reduced FAF (A) and NIA (B) intensity which enlarge during follow-up. The choroidal excavation outside of the macula (green arrows) progressed as well as indicated by the absence of the line of increased reflectance towards the choroid in this and adjacent scans at the follow-up examination.

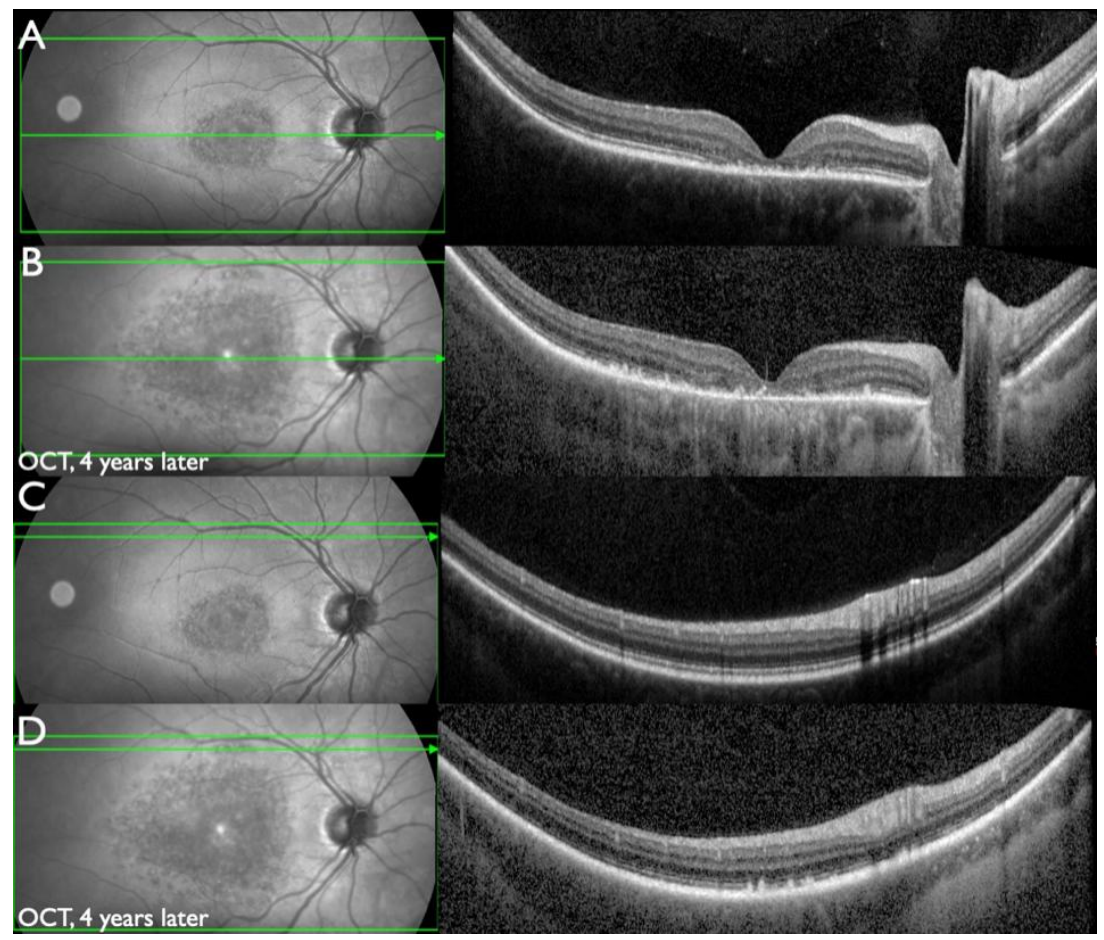

Figure 7. Patient \#27 (14.3 and 18.8 years) with progressive ABCA4-IRD. W-OCT, central horizontal scan: (A) Disintegration of the outer retinal layers in the foveal and parafoveal region. (B) Progressed disintegration in the foveal area as well as peripheral progression of disintegration beyond the macular area (4 years later). W-OCT, superior horizontal scan tangentially to the upper temporal vascular arcade: (C) Normal structure of retinal layers. (D) Flecks of irregular outer retinal layers and SRM (4 years later).

additional tool for disease definition and documentation of progression during follow up. Especially for 
treatment trials, it will be important to evaluate areas not covered by M-OCT to define markers for monitoring of treatment effects.

In addition, as shown previously in myopic eyes ${ }^{[30]}, \mathrm{W}$-OCT allows identifying posterior staphyloma or dome-shaped bulbus configuration in myopic eyes. Within this series, foveal cavitation and optic disc drusen were seen in only one patient each (1.9\%). In contrast to BEST1-associated retinal dystrophies ${ }^{[41]}$, focal choroidal excavation was observed at the posterior pole in only two eyes of two ABCA4-IRD patients and in addition in the mid-periphery in a another eye of one patient $(3 / 104 ; 2.8 \%)$, supporting that it is rare in $A B C A 4$-associated disorders ${ }^{[42]}$.

The findings resulting from FAF and NIA evaluation are comparable to previous reports, indicating that NIA findings usually are more progressed and severe compared to FAF findings ${ }^{[5-8]}$. The frequency of peripapillary sparing was within the range reported previously ${ }^{[43]}$, indicating that peripapillary sparing may lead to suspect ABCA4-IRD but is not a characteristic biomarker.

\section{DECLARATIONS}

\section{Authors' contributions}

Made substantial contributions to conception and design of the study and performed data analysis and interpretation: Saleh M, Stöhr H, Kiel C, Weber BHF, Kellner U

Performed data acquisition, as well as provided administrative, technical, and material support: Kellner S, Weinitz S, Farmand G, Lommatsch A, Weber BHF, Kellner U

\section{Availability of data and materials}

Data cannot be shared as they contain patient specific information.

\section{Financial support and sponsorship}

None.

\section{Conflicts of interest}

All authors declared that there are no conflicts of interest.

\section{Ethical approval and consent to participate}

The ethics committee of the Ärztekammer Nordrhein, Düsseldorf, Germany approved the research.

\section{Consent for publication}

Not applicable.

\section{Copyright}

(c) The Author(s) 2021.

\section{REFERENCES}

1. Cremers FPM, Lee W, Collin RWJ, Allikmets R. Clinical spectrum, genetic complexity and therapeutic approaches for retinal disease caused by ABCA4 mutations. Prog Retin Eye Res 2020;79:100861. DOI PubMed PMC

2. Cornelis SS, Bax NM, Zernant J, et al. In silico functional meta-analysis of 5,962 ABCA4 variants in 3,928 retinal dystrophy cases. Hum Mutat 2017;38:400-8. DOI PubMed

3. Khan M, Cremers FPM. ABCA4-associated stargardt disease. Klin Monbl Augenheilkd 2020;237:267-74. DOI PubMed

4. Schulz HL, Grassmann F, Kellner U, et al. Mutation spectrum of the ABCA4 gene in 335 stargardt disease patients from a multicenter german cohort-impact of selected deep intronic variants and common SNPs. Invest Ophthalmol Vis Sci 2017;58:394-403. DOI PubMed PMC

5. Kellner S, Kellner U, Weber BH, Fiebig B, Weinitz S, Ruether K. Lipofuscin- and melanin-related fundus autofluorescence in patients with ABCA4-associated retinal dystrophies. Am J Ophthalmol 2009;147:895-902, 902.e1. DOI PubMed 
6. Müller PL, Birtel J, Herrmann P, Holz FG, Charbel Issa P, Gliem M. Functional relevance and structural correlates of near infrared and short wavelength fundus autofluorescence imaging in ABCA4-related retinopathy. Transl Vis Sci Technol 2019;8:46. DOI PubMed PMC

7. Greenstein VC, Schuman AD, Lee W, et al. Near-infrared autofluorescence: its relationship to short-wavelength autofluorescence and optical coherence tomography in recessive stargardt disease. Invest Ophthalmol Vis Sci 2015;56:3226-34. DOI PubMed PMC

8. Duncker T, Marsiglia M, Lee W, et al. Correlations among near-infrared and short-wavelength autofluorescence and spectral-domain optical coherence tomography in recessive Stargardt disease. Invest Ophthalmol Vis Sci 2014;55:8134-43. DOI PubMed PMC

9. Hoseini-Yazdi H, Vincent SJ, Collins MJ, Read SA, Alonso-Caneiro D. Repeatability of wide-field choroidal thickness measurements using enhanced-depth imaging optical coherence tomography. Clin Exp Optom 2019;102:327-34. DOI PubMed

10. Hondur G, Göktaş E, Al-Aswad L, Tezel G. Age-related changes in the peripheral retinal nerve fiber layer thickness. Clin Ophthalmol 2018;12:401-9. DOI PubMed PMC

11. Hoseini-Yazdi H, Vincent SJ, Collins MJ, Read SA, Alonso-Caneiro D. Wide-field choroidal thickness in myopes and emmetropes. Sci Rep 2019;9:3474. DOI PubMed PMC

12. Kakiuchi N, Terasaki H, Sonoda S, et al. Regional differences of choroidal structure determined by wide-field optical coherence tomography. Invest Ophthalmol Vis Sci 2019;60:2614-22. DOI PubMed

13. Kim MS, Lim HB, Lee WH, Kim KM, Nam KY, Kim JY. Wide-field swept-source optical coherence tomography analysis of interocular symmetry of choroidal thickness in healthy young individuals. Invest Ophthalmol Vis Sci 2021;62:5. DOI PubMed PMC

14. Lim HB, Kim K, Won YK, Lee WH, Lee MW, Kim JY. A comparison of choroidal thicknesses between pachychoroid and normochoroid eyes acquired from wide-field swept-source OCT. Acta Ophthalmol 2021;99:e117-23. DOI PubMed

15. Singh SR, Invernizzi A, Rasheed MA, et al. Wide-field individual retinal layer thickness in healthy eyes. Eur J Ophthalmol 2020:1120672120927664. DOI PubMed

16. Singh SR, Invernizzi A, Rasheed MA, et al. Wide-field choroidal vascularity in healthy eyes. Am J Ophthalmol 2018;193:100-5. DOI PubMed

17. Tan O, Liu L, Liu L, Huang D. Nerve fiber flux analysis using wide-field swept-source optical coherence tomography. Transl Vis Sci Technol 2018;7:16. DOI PubMed PMC

18. Hood DC, De Cuir N, Blumberg DM, et al. A single wide-field OCT protocol can provide compelling information for the diagnosis of early glaucoma. Transl Vis Sci Technol 2016;5:4. DOI PubMed PMC

19. Lee WJ, Kim TJ, Kim YK, Jeoung JW, Park KH. Serial combined wide-field optical coherence tomography maps for detection of early glaucomatous structural progression. JAMA Ophthalmol 2018;136:1121-7. DOI PubMed PMC

20. Lee WJ, Oh S, Kim YK, Jeoung JW, Park KH. Comparison of glaucoma-diagnostic ability between wide-field swept-source OCT retinal nerve fiber layer maps and spectral-domain OCT. Eye (Lond) 2018;32:1483-92. DOI PubMed PMC

21. Muhammad H, Fuchs TJ, De Cuir N, et al. Hybrid deep learning on single wide-field optical coherence tomography scans accurately classifies glaucoma suspects. J Glaucoma 2017;26:1086-94. DOI PubMed PMC

22. Yoshida M, Kunimatsu-Sanuki S, Omodaka K, Nakazawa T. Predicting the integrated visual field with wide-scan optical coherence tomography in glaucoma patients. Curr Eye Res 2018;43:754-61. DOI PubMed

23. Hirano T, Kakihara S, Toriyama Y, Nittala MG, Murata T, Sadda S. Wide-field en face swept-source optical coherence tomography angiography using extended field imaging in diabetic retinopathy. Br J Ophthalmol 2018;102:1199-203. DOI PubMed

24. Kim K, In You J, Park JR, Kim ES, Oh WY, Yu SY. Quantification of retinal microvascular parameters by severity of diabetic retinopathy using wide-field swept-source optical coherence tomography angiography. Graefes Arch Clin Exp Ophthalmol 2021. DOI PubMed

25. Munk MR, Lincke J, Giannakaki-Zimmermann H, Ebneter A, Wolf S, Zinkernagel MS. Comparison of $55^{\circ}$ wide-field spectral domain optical coherence tomography and conventional $30^{\circ}$ optical coherence tomography for the assessment of diabetic macular edema. Ophthalmologica 2017;237:145-52. DOI PubMed

26. Sawada O, Ichiyama Y, Obata S, et al. Comparison between wide-angle OCT angiography and ultra-wide field fluorescein angiography for detecting non-perfusion areas and retinal neovascularization in eyes with diabetic retinopathy. Graefes Arch Clin Exp Ophthalmol 2018;256:1275-80. DOI PubMed

27. Wang M, Garg I, Miller JB. Wide field swept source optical coherence tomography angiography for the evaluation of proliferative diabetic retinopathy and associated lesions: a review. Semin Ophthalmol 2021;36:162-7. DOI PubMed

28. Singh SR, Invernizzi A, Rasheed MA, et al. Wide-field choroidal vascular analysis in central serous chorioretinopathy. Eur $J$ Ophthalmol 2020:1120672120963456. DOI PubMed

29. Xiao W, Zhu Z, Odouard C, Xiao O, Guo X, He M. Wide-field en face swept-source optical coherence tomography features of extrafoveal retinoschisis in highly myopic eyes. Invest Ophthalmol Vis Sci 2017;58:1037-44. DOI PubMed

30. Zheng F, Wong CW, Sabanayagam C, et al. Prevalence, risk factors and impact of posterior staphyloma diagnosed from wide-field optical coherence tomography in Singapore adults with high myopia. Acta Ophthalmol 2021;99:e144-53. DOI PubMed

31. Greenstein VC, Nunez J, Lee W, et al. A comparison of en face optical coherence tomography and fundus autofluorescence in stargardt disease. Invest Ophthalmol Vis Sci 2017;58:5227-36. DOI PubMed PMC

32. Kumar V, Kumawat D, Tewari R, Venkatesh P. Ultra-wide field imaging of pigmented para-venous retino-choroidal atrophy. Eur $J$ Ophthalmol 2019;29:444-52. DOI PubMed

33. Zhang T, Wang Z, Sun L, et al. Ultra-wide-field scanning laser ophthalmoscopy and optical coherence tomography in FEVR: findings and its diagnostic ability. Br J Ophthalmol 2021;105:995-1001. DOI PubMed

34. Han IC, Whitmore SS, Critser DB, et al. Wide-field swept-source OCT and angiography in X-linked retinoschisis. Ophthalmol Retina 


\section{9;3:178-85. DOI PubMed}

35. Richards S, Aziz N, Bale S, et al; ACMG Laboratory Quality Assurance Committee. Standards and guidelines for the interpretation of sequence variants: a joint consensus recommendation of the American College of Medical Genetics and Genomics and the Association for Molecular Pathology. Genet Med 2015;17:405-24. DOI PubMed PMC

36. Jaakson K, Zernant J, Külm M, et al. Genotyping microarray (gene chip) for the ABCR (ABCA4) gene. Hum Mutat 2003;22:395-403. DOI PubMed

37. RDC. R: A language and environment for statistical computing. Available from: http://www.R-project.org [Last accessed on $23 \mathrm{Jul}$ 2021].

38. Campbell JP, Nudleman E, Yang J, et al. Handheld optical coherence tomography angiography and ultra-wide-field optical coherence tomography in retinopathy of prematurity. JAMA Ophthalmol 2017;135:977-81. DOI PubMed PMC

39. McNabb RP, Polans J, Keller B, et al. Wide-field whole eye OCT system with demonstration of quantitative retinal curvature estimation. Biomed Opt Express 2019;10:338-55. DOI PubMed PMC

40. Runhart EH, Sangermano R, Cornelis SS, et al. The common ABCA4 variant p.Asn1868Ile shows nonpenetrance and variable expression of stargardt disease when present in trans with severe variants. Invest Ophthalmol Vis Sci 2018;59:3220-31. DOI PubMed

41. Hufendiek K, Hufendiek K, Jägle H, et al. Clinical heterogeneity in autosomal recessive bestrophinopathy with biallelic mutations in the BEST1 gene. Int J Mol Sci 2020;21:9353. DOI PubMed PMC

42. Parodi M, Casalino G, Iacono P, Introini U, Adamyan T, Bandello F. The expanding clinical spectrum of choroidal excavation in macular dystrophies. Retina 2018;38:2030-4. DOI PubMed

43. Boulanger-Scemama E, Mohand-Saïd S, El Shamieh S, et al. Phenotype analysis of retinal dystrophies in light of the underlying genetic defects: application to cone and cone-rod dystrophies. Int J Mol Sci 2019;20:4854. DOI PubMed PMC 